\title{
Effects of tight computerized glucose control on neurological outcome in severely brain injured patients: a multicenter sub-group analysis of the randomized-controlled open-label CGAO-REA study
}

Raphaël Cinotti ${ }^{1}$, Carole Ichai ${ }^{2,3}$, Jean-Christophe Orban ${ }^{2,3}$, Pierre Kalfon ${ }^{4}$, Fanny Feuillet ${ }^{5,6}$, Antoine Roquilly ${ }^{7,8}$, Bruno Riou ${ }^{9,10}$, Yvonnick Blanloeil ${ }^{1}$, Karim Asehnoune ${ }^{7,8}$ and Bertrand Rozec ${ }^{1,11^{*}}$

\begin{abstract}
Introduction: Hyperglycemia is a marker of poor prognosis in severe brain injuries. There is currently little data regarding the effects of intensive insulin therapy (IIT) on neurological recovery.

Methods: A sub-group analysis of the randomized-controlled CGAO-REA study (NCT01002482) in surgical intensive care units (ICU) of two university hospitals. Patients with severe brain injury, with an expected ICU length of stay $\geq 48$ hours were included. Patients were randomized between a conventional glucose management group (blood glucose target between 5.5 and $9 \mathrm{mmol.L}^{-1}$ ) and an IIT group (blood glucose target between 4.4 and 6 mmol..-1 ${ }^{-1}$. The primary outcome was the day-90 neurological outcome evaluated with the Glasgow outcome scale.
\end{abstract}

Results: A total of 188 patients were included in this analysis. In total 98 (52\%) patients were randomized in the control group and 90 (48\%) in the IIT group. The mean Glasgow coma score at baseline was $7( \pm 4)$. Patients in the IIT group received more insulin (130 (68 to 251 ) IU versus 74 (13 to 165 ) IU in the control group, $P=0.01$ ), had a significantly lower morning blood glucose level (5.9 (5.1 to 6.7) $\mathrm{mmol}^{-L^{-1}}$ versus 6.5 (5.6 to 7.2$) \mathrm{mmol} . \mathrm{L}^{-1}, P<0.001$ ) in the first 5 days after ICU admission. The IIT group experienced more episodes of hypoglycemia $(P<0.0001)$. In the IIT group 24 (26.6\%) patients had a favorable neurological outcome (good recovery or moderate disability) compared to 31 (31.6\%) in the control group $(P=0.4)$. There were no differences in day-28 mortality. The occurrence of hypoglycemia did not influence the outcome.

Conclusions: In this sub-group analysis of a large multicenter randomized trial, IIT did not appear to alter the day-90 neurological outcome or ICU morbidity in severe brain injured patients or ICU morbidity.

\section{Introduction}

Numerous studies are available regarding blood glucose (BG) control in the intensive care unit (ICU) setting [1,2] and have led to the elaboration of international guidelines $[3,4]$. On the other hand, randomized controlled trials

\footnotetext{
* Correspondence: bertrand.rozec@chu-nantes.fr

'Service d'Anesthésie-Réanimation. Hôpital Guillaume et René Laennec, Boulevard Jacques Monod, 44800 Saint-Herblain, CHU de Nantes 44093 cedex, France

${ }^{11}$ Institut du thorax, INSERM UMR1087 IRT, UN 8 quai Moncousu, BP 7072 44007 Nantes Cedex 1, France

Full list of author information is available at the end of the article
}

focusing on severely brain-injured patients, such as those with traumatic brain injury (TBI) or intra-cerebral hemorrhage (ICH), are scarce. Clinical studies are monocentric [5], frequently retrospective [6] and performed in small cohorts of patients [7]. Large randomized controlled trials did not evaluate specifically the impact of tight glucose control on neurological outcome in this specific ICU population [2]. Moreover, all of these studies have shown that this strategy increases the incidence of hypoglycemia that has been identified as an independent risk factor of mortality in the general-ICU setting [8] and has 
been advocated to increase cerebral glutamate and lactate/ pyruvate ratio in TBI patients [9]. Therefore, balancing the potential beneficial effect of normalizing $B G$ to the higher risk of hypoglycemia is a real matter of debate in brain-injured patients. Hyperglycemia has been clearly identified as a marker of poor outcome in TBI [10], cardiac arrest [11], ICH [12] and stroke [13]. If BG control appears mandatory in the neuro-ICU setting to prevent secondary brain damage and improve patient's outcome [14], the appropriate BG target remains unclear.

Not only normoglycemia, but insulin itself has been reported to improve critically ill patients considering its metabolic and anti-inflammatory effects $[15,16]$. Experimental data suggest that insulin could increase astrocyte glucose uptake [17] and could play a role in cerebral glucose regulation in the cortex [18]. Finally, BG level after brain injury is more dependent on cerebral glucose utilization than BG level itself meaning that the appropriate glucose target to reach after brain insult remains unknown [19]. We conducted a sub-group analysis of a multicenter randomized-controlled open study (CGAOREA study-NCT01002482) [20] regarding the effects of intensive insulin therapy (IIT) on neurological outcome in severely brain-injured patients.

\section{Material and methods}

This study was a sub-group analysis of the non-blinded parallel-group randomized controlled CGAO-REA study (NCT01002482) [20] performed in two ICUs of French university hospitals (Nantes and Nice). Written informed consent was obtained before randomization, or delayed consent was obtained from each patient whenever neurological recovery was deemed appropriate or from a legal surrogate. The CGAO-REA study and ancillary studies were approved by the Ethics Committee of the teaching hospital of Tours, France.

\section{Inclusion criteria}

As described in the CGAO-REA study, adults who required at least three days of ICU stay were eligible for this study. Patients in a moribund state at admission were not eligible.

All patients with a severe brain injury, with an expected ICU length of stay of at least three days at admission who were included in the CGAO-REA study, were eligible for this sub-group analysis; brain injuries included: TBI, aneurysmal subarachnoid hemorrhage (SAH), stroke, $\mathrm{ICH}$ without aneurysm, resuscitated cardiac arrest, brain tumor, cerebral abscess or central nervous system infection.

\section{Brain injury management}

Brain-injured patients with a Glasgow coma score (GCS) $\leq 8$ were intubated and were mechanically ventilated
[21]. Patients were sedated with either midazolam $(0.2$ to $0.5 \mathrm{mg} \cdot \mathrm{kg}^{-1} \cdot \mathrm{h}^{-1}$ ) or propofol ( 1 to $5 \mathrm{mg} \cdot \mathrm{kg}^{-1} \cdot \mathrm{h}^{-1}$ ) and continuous infusion of fentanyl (2 to $5 \mu \mathrm{g} \cdot \mathrm{kg}^{-1} \cdot \mathrm{h}^{-1}$ ) or sufentanil $\left(0.2\right.$ to $\left.0.5 \mu \mathrm{g} \cdot \mathrm{kg}^{-1} \cdot \mathrm{h}^{-1}\right)$. Management of patients was consistent with the guidelines of the Brain Trauma Foundation [22]. Subsequently, intra-cerebral pressure (ICP) monitoring was performed in patients with GCS $\leq 8$ and with an abnormal brain computed tomography $(\mathrm{CT})$ scan or whenever deemed appropriate by the attending intensivist, using either an intraparenchymental device or a ventriculostomy in the presence of hydrocephalus [23]. Cerebral perfusion pressure (CPP) was maintained in the range of 60 to $70 \mathrm{mmHg}$ $[21,22]$ with continuous infusion of norepinephrine when needed $[21,22]$. Since there is little evidence in the setting of neuro-vascular diseases regarding CPP thresholds, the same thresholds were applied in patients with ICP monitoring other than TBI, with respect to specific management, such as blood pressure targets following SAH or ICH [23]. To prevent secondary brain insults, the following standards of care were also applied: normoxia $\left(\mathrm{PaO}_{2} \geq 80 \mathrm{mmHg}\right)$, normocapnia $\left(35 \leq \mathrm{PCO}_{2} \leq\right.$ $45 \mathrm{mmHg}$ ), body temperature between $36^{\circ} \mathrm{C}$ and $38^{\circ} \mathrm{C}$ and maintenance of a serum osmolality ranging between 280 and 320 mOsm. $\mathrm{kg}^{-1}$ [24].

Intracranial hypertensive episodes defined by an ICP $\geq 20 \mathrm{mmHg}$ [22], were treated by boli of sedatives and a bolus of mannitol (0.5 g. $\left.\mathrm{kg}^{-1}\right)$ [25]. Mannitol was used in the setting of plasma osmolality $\leq 320$ mosm. $\mathrm{kg}^{-1}$. In the case of refractory intracranial hypertension (ICP $\geq 20 \mathrm{mmHg}$ for more than 15 minutes despite usual first-line treatment) [22], barbiturates (sodium thiopental) were added with an intravenous bolus of 2 to $3 \mathrm{mg} \cdot \mathrm{kg}^{-1}$ followed by a continuous infusion of 2 to $3 \mathrm{mg} \cdot \mathrm{kg}^{-1} \cdot \mathrm{h}^{-1}$ [26]. Twenty-four hour therapeutic mild-hypothermia was a standard of care regarding resuscitated cardiac arrest [27] and was discussed in the setting of refractory ICP hypertension [28].

Sedation was stopped whenever the control of ICP was deemed appropriate.

\section{Blood glucose management}

In the CGAO study, randomization was stratified according to the type of admission (scheduled surgical, emergency surgical, medical), diabetic status prior admission and conventional glucose control management in the ICU before the beginning of the study. BG management is described elsewhere [20]. Briefly, patients were included in the standard of care group (Control group) or the IIT group. In the IIT group, tight computerized BG control was performed with the assistance of the CGAO (Contrôle glycémique assisté par Ordinateur) software $\left(\mathrm{LK}^{2 \oplus}\right.$, Saint-Avertin, France) set for targeting a BG range between 4.4 and $6 \mathrm{mmol} \cdot \mathrm{L}^{-1}$. The CGAO 
software is an open-loop computer decision support system for BG control management that produces, at bedside, explicit recommendations regarding not only insulin titration (with an algorithm based on a proportional integral controller [29]), but also time for the next BG measurement and dose of intravenous glucose for correction of a possible hypoglycemia. The attending nurse could accept or decline the CGAO recommendations after each BG measurement, in the case of high doses of insulin administration which could lead to hypoglycemia. Nurses could ask the attending physician for assistance. In the control arm, BG management was based on current practice already used in the participating ICU before the beginning of the study and the targeted BG range was between 6 and $9 \mathrm{mmol} . \mathrm{L}^{-1}$ in Nantes and between 5.5 and $9 \mathrm{mmol} . \mathrm{L}^{-1}$ in Nice. All patients underwent an enteral nutrition protocol which included early initiation of enteral nutrition (day 1 after ICU admission), enteral intake target of 20 to $30 \mathrm{kCal} . \mathrm{kg}^{-1}$.day ${ }^{-1}$ [30] and the absence of residual gastric volume monitoring.

\section{Data collection}

Patient characteristics and neurologic data at baseline were analyzed as well as BG level and mean doses of insulin within the first five days which was considered as the acute phase of brain-injury and intra-cerebral hypertension. Episodes of moderate $\left(<3.3 \mathrm{mmol} . \mathrm{L}^{-1}\right)$ and severe $\left(<2.2 \mathrm{mmol} . \mathrm{L}^{-1}\right)$ hypoglycemia were recorded.

\section{Outcome measures}

The primary outcome was the neurologic outcome at day 90 following ICU admission and was assessed using the Glasgow outcome scale (GOS) via phone call blinded to treatment group [24]. Patients were dichotomized into good neurologic outcome defined by a good recovery and moderate disability (GOS 1 to 2) and poor neurologic outcome regarded as severe disability, vegetative state and death $(\mathrm{GOS} 3,4,5)$. Secondary outcomes were: neurosurgical events during ICU stay, in-ICU death, neurologic outcome at day 28 following ICU admission, 28-day-ICUfree days and 28-day-ventilator-free days.

\section{Statistical analysis}

Continuous data are expressed as mean \pm standard deviation for parametric data and as median $\left(25^{\text {th }}\right.$ to 75 th percentiles) for non-parametric data. Categorical data are expressed as number (\%). A univariate analysis was performed regarding the primary and secondary outcomes between the control and the intervention groups. Parametric and non-parametric values were compared using the unpaired Student $t$-test and Mann-Whitney tests, respectively. Categorical values were compared with the $\mathrm{chi}^{2}$ test. We also performed a multivariate analysis regarding the risk factors of day 90 good neurological outcome [24]. Factors identified as potential prognosis factors for day 90 good neurological outcome by the univariate analysis with a cut-off $P$ value at 0.2 were included in the logistic regression model and backward selection was applied. The calibration of the model was tested by a Hosmer-Lemeshow's test. The final model was presented with a crude odds ratio (OR) and $95 \%$ confidence interval (CI). All $P$ values were two-tailed and $P$ values less than 0.05 were considered significant. Statistical analysis was performed with SAS statistical software (SAS 9.3 Institute, Cary, NC, USA).

\section{Results}

A total of 496 patients from the ICUs of Nantes and Nice were included in the CGAO-REA study, and 188 of them (37\%) were included in our sub-group analysis focused on brain-injured patients. Ninety four patients were included per center. Ninety $(48 \%)$ patients were included in the IIT group and 98 (52\%) in the control group. One hundred and seventy eight (95\%) patients underwent mechanical ventilation for at least two days. The two groups were comparable except for GCS and body mass index (BMI), which were lower in the IIT group. In addition, more patients received ICP monitoring in the intervention group $(\mathrm{n}=47,52.2 \%)$ than in the control group $(\mathrm{n}=34,34.6 \%)(P=0.01)$. Patient characteristics are provided in Table 1.

Each morning laboratory BG was significantly lower in the IIT group (5.9 (5.1 to 6.7) $\mathrm{mmol}^{-\mathrm{L}^{-1}}$ ) than in the control group (6.5 (5.6 to 7.2) mmol. $\mathrm{L}^{-1}$ ) during the first five days of ICU hospitalization $(P<0.001)$. In the IIT group, patients received significantly higher doses of insulin (130 (68 to 251 ) IU versus 74 (13 to 165$)$ IU in the control group $(P=0.01)$ ), within the first five days of ICU hospitalization. There were significantly more episodes of moderate hypoglycemia in the IIT group $(n=46,51.1 \%)$ than in the control group $(\mathrm{n}=19,19.3 \%)(P<0.001)$. Six $(6.67 \%)$ patients experienced an episode of severe hypoglycemia in the IIT group and four $(4 \%)$ in the control group $(P=0.5)$. In-ICU glycemic events are summarized in Table 2.

\section{Outcomes}

In the IIT group, $24(26.6 \%)$ patients had a favorable neurological outcome (good recovery, moderate disability) compared to $32(31.6 \%)$ in the control group $(P=0.40)$ (Figure 1). There were no significant differences regarding the day-28 neurological outcome, in-ICU death, the number of ventilation-free days and the number of ICU-free days (Table 3). There were no significant differences regarding in-ICU neuro-surgical events (Table 4). The occurrence of hypoglycemia did not significantly modify the day-90 neurological outcome $(P=0.70)$. 
Table 1 Characteristics of severe-brain injured patients

\begin{tabular}{lccc}
\hline & $\begin{array}{c}\text { Control group } \\
\text { Number }=\mathbf{9 8}\end{array}$ & $\begin{array}{c}\text { IIT group } \\
\text { Number }=90\end{array}$ & P value \\
\hline Age & $53(15)$ & $53(16)$ & 0.90 \\
SAPS II & $45(15)$ & $47(17)$ & 0.50 \\
GCS on admission & $7(4)$ & $6(3)$ & 0.02 \\
Sex male/female & $60(61) / 38(39)$ & $51(56) / 39(44)$ & 0.50 \\
BMI & $26(5)$ & $24(4)$ & 0.02 \\
Diabetes mellitus & $9(9.2)$ & $4(4.4)$ & 0.20 \\
Laboratory glycemia & $8.1(6.8$ to 9.8) & $8.3(6.8$ to 9.6) & 0.50 \\
on admission (mmol.-1 $)$ & & & \\
Monitoring of ICP & $34(35)$ & $47(52)$ & $0.01^{*}$ \\
Cause of brain injury, & & & 0.50 \\
number(\%) & & & \\
Traumatic brain injury & $19(19)$ & $22(24)$ & \\
Aneurysmal subarachnoid & $28(29)$ & $32(36)$ & \\
hemorrhage & $12(12)$ & $10(11)$ & \\
Intra-cerebral hemorrhage & $11(11)$ & $5(6)$ & \\
Malignant stroke & $13(13)$ & $13(14)$ & \\
Resuscitated cardiac arrest & $15(15)$ & $8(9)$ & \\
Other & & & \\
\hline
\end{tabular}

Characteristics of patients included in the CGAO-REA study and suffering from a severe brain injury, in two neuro-intensive care units of two university hospitals. Continuous parametric data are expressed as mean (standard deviation) and non-parametric data as median ( $25^{\text {th }}$ to $75^{\text {th }}$ percentile) and categorical data as number (\%). Continuous data were analyzed with Student's $t$ test. Categorical data were analyzed with $\mathrm{x}^{2}$ test. BMI: body mass index $\left(\mathrm{kg} \cdot \mathrm{m}^{-2}\right)$; GCS: Glasgow Coma Score; ICP: intracerebral pressure; IIT: intensive insulin therapy; SAPS II: Simplified Acute Physiology Score II.

Prognosis factors of favorable day-90 neurological outcome On univariate analysis, the prognosis factors of favorable neurological outcome were: other cause of brain injury than brain trauma, the absence of decompressive craniectomy, the absence of nosocomial pneumonia during ICU hospitalization, lower blood glucose level at ICU admission, administration during ICU of anti-epileptic

Table 2 In-ICU blood glucose events

\begin{tabular}{|c|c|c|c|}
\hline & $\begin{array}{l}\text { Control group } \\
\text { Number }=98\end{array}$ & $\begin{array}{l}\text { IIT group } \\
\text { Number }=90\end{array}$ & $P$ value \\
\hline $\begin{array}{l}\text { Median of the first five } \\
\text { days morning laboratory } \\
\text { blood glucose (mmol. } .^{-1} \text { ) }\end{array}$ & 6.5 (5.6 to 7.2$)$ & $5.9(5.1$ to 6.7$)$ & $<0.001^{a}$ \\
\hline $\begin{array}{l}\text { Episodes of moderate } \\
\text { hypoglycemia }\end{array}$ & $19(19.3)$ & $46(51.1)$ & $<0.001^{\mathrm{b}}$ \\
\hline $\begin{array}{l}\text { Episodes of severe } \\
\text { hypoglycemia }\end{array}$ & $4(4)$ & $6(6.6)$ & 0.50 \\
\hline Patients treated with insulin & $81(82.6)$ & $87(96.6)$ & $0.002^{b}$ \\
\hline $\begin{array}{l}\text { Total of insulin dose (IU) } \\
\text { in the first five days }\end{array}$ & 74 (13 to 165$)$ & $130(68$ to 251 & $0.01^{\mathrm{a}}$ \\
\hline
\end{tabular}

${ }^{a}$ Student's t test; ${ }^{b} X^{2}$ test. Moderate hypoglycemia was define as a blood glucose level $<3.3 \mathrm{mmol} . \mathrm{L}^{-1}$. Severe hypoglycemia was defined as $<2.2 \mathrm{mmol} \mathrm{L}^{-1}$. Continuous data are expressed as median ( $25^{\text {th }}$ to 75 th percentile) and categorical data as $\mathrm{N}(\%)$. IIT: intensive insulin therapy.

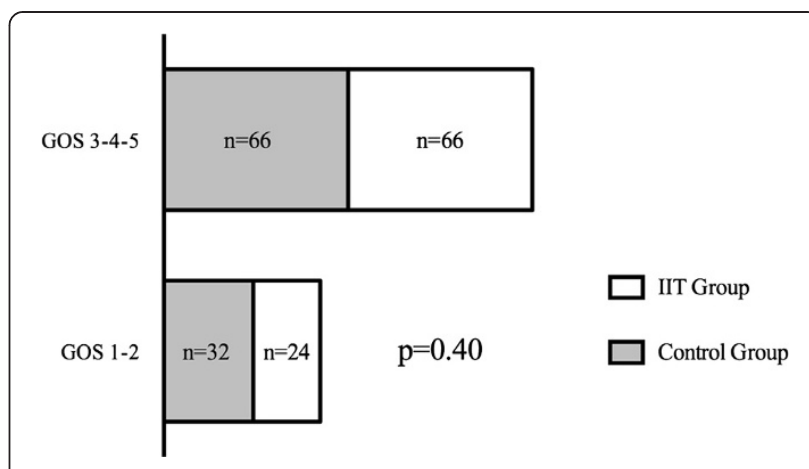

Figure 1 Day 90 neurological outcome following ICU admission. The figure represents the day-90 neurological outcome after ICU admission in severely brain-injured patients in the control group (blood glucose range between 5.5 and 9 mmol... ${ }^{-1}$ ) and the intensive insulin therapy (IIT) group (blood glucose range between 4.4 and 6 mmol.L ${ }^{-1}$ ). Good neurological outcome is classified as a Glasgow outcome scale (GOS) score of 1 to 2 (good recovery, moderate disability). Poor neurological outcome is classified as a GOS score of 3, 4 or 5 (severe disability, vegetative state, death). $x^{2}$ test.

drugs, a higher administration of insulin dose in the first five days after ICU admission and a higher number of ventilation-free days. In the multivariate analysis, all causes of brain injury except trauma, administration of anti-epileptic drugs and a higher number of ventilationfree days were independent and significant prognosis factors of favorable outcome (Table 5).

\section{Discussion}

Our study shows that tight computerized BG control had no significant effect on neurological recovery at day- 90 following ICU admission in the sub-group of brain-injured patients extracted from the multi-center randomizedcontrolled CGAO-REA trial. The incidence of moderate hypoglycemia was higher in the IIT group but this did not significantly modify neurological outcome.

Acute neurological injuries bear significant mortality and are one of the major causes of severe disability

Table 3 Outcome of severely brain-injured patients

\begin{tabular}{lccc}
\hline & $\begin{array}{c}\text { Control group } \\
\text { Number }=\mathbf{9 8}\end{array}$ & $\begin{array}{l}\text { IIT group } \\
\text { Number }=\mathbf{9 0}\end{array}$ & P value \\
\hline Ventilation-free days & 8.5 (0 to 22) & 9 (0 to 20) & 0.40 \\
ICU-free days & 8.5 (0 to 20) & $8(0$ to 20) & 0.50 \\
Day-28 mortality & $28(28.6)$ & $26(28.9)$ & 0.90 \\
$\begin{array}{l}\text { Day-28 good } \\
\text { neurologic outcome }\end{array}$ & $31(31.6)$ & $24(26.6)$ & 0.40 \\
\hline
\end{tabular}

Crude outcome of severely brain-injured patients included in a sub-group analysis of the CGAO-REA study. Ventilation and ICU-free days are expressed between ICU admission and Day-28. Good neurologic outcome was defined as a good recovery or moderate disability (Glasgow outcome scale score 1 to 2 ) [24]. Poor neurologic outcome was defined as severe disability or vegetative state or death (Glasgow outcome scale score 3, 4, 5) [24]. Continuous data are expressed as median ( $25^{\text {th }}$ to $75^{\text {th }}$ percentile) and categorical data as number (\%). Continuous data were analyzed with Student's t test. Categorical data were analyzed with $\mathrm{X}^{2}$ test. IIT: intensive insulin therapy. 
Table 4 Neuro-surgical events in the ICU in severely brain-injured patients

\begin{tabular}{|c|c|c|c|}
\hline & Control group & IIT group & $P$ value \\
\hline & Number $=98$ & Number $=90$ & \\
\hline $\begin{array}{l}\text { Patients presenting at least one episode of ICP } \geq 25 \mathrm{mmHg} \\
\text { during ICP monitoring }\end{array}$ & $17(17.3)$ & $23(25.5)$ & 0.20 \\
\hline Administration of mannitol during ICU & $19(19.4)$ & $28(31.1)$ & $0.06^{*}$ \\
\hline Barbiturates use during ICU & $9(9.2)$ & $14(15.6)$ & 0.20 \\
\hline
\end{tabular}

Specific neuro-surgical events in the ICU in a sub-group analysis of severely brain-injured patients in two university hospitals of the CGAO-REA study. Categorical data are expressed as number (\%) and analyzed with $X^{2}$ test. ICP: intra-cerebral pressure; IIT: intensive insulin therapy.

among young healthy individuals in western countries and incur substantial health-care costs [23,31]. Hyperglycemia is a well-recognized secondary brain insult and is a marker of poor outcome in every brain-injured patient, leading to increased brain damage [10]. BG control is, therefore, mandatory and has proved efficacious in improving neurological outcome in stroke [14]. However, such results have not been clearly evaluated in ICU patients with neurologic diseases and high ICP. Few studies have been performed in the neuro-ICU setting. In a single center randomized study IIT did not result in any neurologic improvement in a critically ill neurologic population [32]. In a large series of $178 \mathrm{SAH}$ patients, the authors pointed out that an elevated BG level $\left(>7.8 \mathrm{mmol} . \mathrm{L}^{-1}\right)$ was associated with a poorer outcome, but most patients displayed a mild to moderate form of SAH [33]. Also, the authors used a conventional BG control. In a large retrospective analysis of a single-center cohort of various neurologic injuries, Graffignano et al. [6] reported that IIT was associated with more episodes of hypoglycemia, an increased in-hospital length of stay and a higher mortality. In this study, the severity of neurologic injury and the occurrence of intracranial hypertension were unknown [6]. It is, therefore, difficult to draw conclusions from such studies about the appropriate BG level to target in the neuro-ICU setting.

\section{Table 5 Exploratory multivariate analysis of risk factors of day-90 favorable neurological outcome}

\begin{tabular}{|c|c|c|c|}
\hline & Adjusted OR & $\mathrm{Cl}_{95 \%}(\mathrm{OR})$ & $P$ value \\
\hline Cause of brain injury & & & 0.004 \\
\hline Traumatic brain injury & 1 & & \\
\hline $\begin{array}{l}\text { Neuro-vascular cause } \\
\text { (SAH, ICH, malignant stroke) }\end{array}$ & 1.27 & (0.46 to 3.54$)$ & \\
\hline Resuscitated cardiac arrest & 3.99 & (1.02 to 15.61$)$ & \\
\hline $\begin{array}{l}\text { Other etiologies (brain tumor, } \\
\text { central nervous system } \\
\text { infection, cerebral vascularitis) }\end{array}$ & 7.92 & (2.10 to 29.91$)$ & \\
\hline Anti-epileptic drugs & 2.99 & (1.10 to 8.16$)$ & 0.03 \\
\hline Number of ventilation-free days & 1.11 & (1.07 to 1.16$)$ & $<0.001$ \\
\hline \multicolumn{4}{|c|}{$\begin{array}{l}\text { Risk factors of day- } 90 \text { favorable neurological outcome defined as good recovery } \\
\text { and moderate disability. Hosmer and Lemeshow goodness-of-fit test } P=0.94 \text {. } \\
\mathrm{Cl}_{95 \%} \text { : } 95 \% \text { confidence interval; ICH: intracerebral hemorrhage; OR: odds ratio; } \\
\text { SAH: subarachnoid hemorrhage. }\end{array}$} \\
\hline
\end{tabular}

Yang et al. [5] performed a randomized controlled study in severe traumatic brain-injured patients. Interestingly, the IIT group with a 4.4 to $6.1 \mathrm{mmol} . \mathrm{L}^{-1}$ target exhibited a lower infections rate, lower ICU length of stay and a better six-month neurologic outcome evaluated with the GOS. The main drawback in this study is that the control group received insulin only when patients had a BG level $>11.1 \mathrm{mmol} . \mathrm{L}^{-1}$, which is not a standard of care [2], and no data were available regarding the management of insulin. In experimental rat models of TBI, the provision of glucose has been reported to improve cerebral metabolism and decrease neuronal injury [34], and insulin resulted in an increased astrocyte glucose uptake [17], suggesting that a large intake of glucose combined with a high insulin infusion after acute neurological injury could prevent secondary brain damages. To the best of our knowledge, we provide the first results obtained in a multi-center study regarding BG management in severely brain-injured patients and we failed to demonstrate any significant difference in the neurological outcome between patients treated with IIT or conventional BG control.

It is noteworthy that a slight lowering in BG levels in our intervention group was associated with a higher incidence of moderate hypoglycemia. Several studies suggest that hypoglycemia is an independent mortality factor in the ICU [2], which was not observed in the CGAO-REA study [20]. Data regarding hypoglycemia and neurologic diseases are conflicting. In a study including 14 consecutive TBI patients undergoing IIT, Vespa et al. [35] demonstrated an increased cerebral glutamate and lactate/ pyruvate ratio and low cerebral glucose assessed with local microdialysis. There was, however, no relationship between serum glucose rates and global rates of glycolysis, evaluated with positron emission tomography suggesting the possible lack of connection between serum and cerebral glucose. In this study, it is also unknown whether these cerebral stress markers have long-term clinical consequences [35]. Moreover, recent data suggest a neuroprotective role of lactate during hypoglycemia, as the brain shifts lactate utilization over glucose, when both substrates are available [36]. In an experimental model, Suh et al. [37] have recently demonstrated that BG reperfusion is responsible for neuronal cell death after hypoglycemia which was not responsible per se for neuronal apoptosis. 
Finally, in our study, as well as other ICU studies regarding BG control, several relevant hypoglycemia severity markers [38], such as duration of hypoglycemic episodes and hypoglycemic-related neurological signs, are not available, mostly because of sedation or previous neurological impairment. Put together, all these issues make it difficult to ascertain the potential neurological consequences of hypoglycemia in severely brain-injured patients.

Risk factors associated with favorable neurological outcome were resuscitated cardiac arrest or miscellaneous causes of brain injury compared to TBI, the administration of anti-epileptic drugs during ICU stay and the number of ventilation-free days (Table 5). Studies in resuscitated cardiac arrest usually focus on in-hospital mortality and neurological status at hospital discharge [39], which makes it difficult to compare to TBI. This result must be cautiously interpreted and remains purely exploratory. Administration of anti-epileptic drugs in the early course of TBI [40] or SAH [23] is mandatory to prevent secondary seizure following brain injury. However, there is little evidence on whether early seizure prophylaxis improves long-term outcome.

There is growing evidence that respiratory complications frequently occur in brain-injured patients [41] and could impact the outcome [42]. It is therefore interesting that a higher number of ventilation-free days was independently associated with a better outcome in our study. An evidence-based bundle is able to reduce the duration of mechanical ventilation in severely brain-injured-patients [43] but there is not yet enough data to assess the impact of such a strategy on the long-term neurological outcome.

Our study has several limitations. This is a sub-group analysis of a large multi-center study and our results remain purely exploratory. In the initial study [20], there was no stratification on the type or severity of neurologic injury. It is, therefore, possible to retrieve an imbalance of patient's severity. Nonetheless, hyperglycemia is a source of secondary brain damage and a marker of poor prognosis in all types of brain injury and one can expect that IIT could have a potential effect on neurological recovery. Finally, IIT could serve a beneficial role in neurologic recovery; this effect could remain undetected since patients in the IIT group had a greater neurologic severity at baseline (lower GCS in this group). In our centers, barbiturates and osmotherapy were commonly used in the most severe patients. To the best of our knowledge, IIT is not advocated to induce ICP hypertension. We believe that the use of barbiturates and osmotherapy probably reflect the severity of brain injury.

Despite significant differences, BG levels were very close in both groups without any real clinical relevance, blunting a possible clinical impact of close BG control on neurological recovery in severely brain-injured patients. In the same way, the absence of hypoglycemia-related neurological worse outcome must be cautiously interpreted because most of the hypoglycemic episodes were moderate. Lastly, the severity of hypoglycemia was only defined by its biological threshold without considering either the duration of these episodes or the usual clinical signs of hypoglycemia.

\section{Conclusions}

Tight BG control did not result in an improved neurological outcome in severely brain-injured patients but significantly increased the rate of moderate episodes of hypoglycemia. Since the most appropriate BG threshold in this specific ICU-population remains unknown, a moderate BG management goal between 5.5 and 9 mmol. $\mathrm{L}^{-1}$ seems preferable.

\section{Key messages}

- Intensive insulin therapy does not affect outcome in severely brain-injured patients.

- Intensive insulin therapy does not affect ICU morbidity in severely brain-injured patients.

- Hypoglycemia is not a marker of poor neurological outcome in severely brain-injured patients.

\section{Abbreviations}

BG: blood glucose; Cl: confidence interval; CPP: cerebral perfusion pressure; GCS: Glasgow Coma Score; GOS: Glasgow Outcome Scale; ICH: intra-cerebral hemorrhage; ICP: intracranial pressure; IIT: intensive insulin therapy; OR: odds ratio; SAH: subarachnoid hemorrhage; TBI: traumatic brain injury.

\section{Competing interests}

The authors declare that they have no competing interests.

\section{Authors' contributions}

RC designed the study, included patients, retrieved data, analyzed data and wrote the paper. $\mathrm{Cl}$ designed the study, included patients, retrieved data, analyzed data and wrote the paper. JCO included patients, retrieved data and edited the manuscript. PK designed the study and edited the manuscript. FF performed statistical analysis. AR designed the study, analyzed data and edited the manuscript. BR designed the study, analyzed data and edited the manuscript. YB designed the study, analyzed data and edited the manuscript. KA designed the study, analyzed data and wrote the paper. BR designed the study, analyzed data and wrote the paper. All authors read and approved the final manuscript.

\section{Author details}

'Service d'Anesthésie-Réanimation. Hôpital Guillaume et René Laennec, Boulevard Jacques Monod, 44800 Saint-Herblain, CHU de Nantes 44093 cedex, France. ${ }^{2}$ Service de Réanimation médico-chirurgicale, Hôpital Saint-Roch, 5 rue Pierre Dévoluy, 06000 Nice cedex, CHU de Nice, France. ${ }^{3}$ INSERM U907 "Dysfonctionnements métaboliques et diabète : mécanismes et approches thérapeutiques", Faculté de Médecine de Nice, 28 avenue de Valombrose, 06107 Nice, France. ${ }^{4}$ Service de Réanimation polyvalente, Hôpital Louis Pasteur, 4 rue Claude Bernard, 28630 Le Coudray, CH de Chartres, France. ${ }^{5}$ EA 4275 "Biostatistique, pharmaco-épidémiologie et mesures subjectives en santé", Faculté de Pharmacie, Université de Nantes, 1 rue Gaston Veil, 44035 Nantes Cedex 1, France. ${ }^{6}$ Plateforme de Biométrie, Cellule de promotion de la recherche clinique, 1 rue Gaston Veil, 44035 Nantes Cedex 1, France. 'Service d'Anesthésie-Réanimation chirurgicale, Hôtel Dieu, 1 place Alexis Ricordeau, CHU Nantes 44093 cedex, France. ${ }^{8}$ Laboratoire UPRES EA 3826, Thérapeutiques cliniques et expérimentales des Infections, 1 rue Gaston Veil, 44035 Nantes Cedex 1, France. '9Service d'accueil des Urgences, CHU Pitié-Salpétrière, 47-83 boulevard de l'Hôpital, 
AP-HP, 75013 Paris, France. ${ }^{10}$ UMR INSERM 1166, IHU ICAN, Sorbonne Université, UMPC Univ Paris 6, 91 Buolivard de l'Hôpital, 75013 Paris, France. ${ }^{11}$ Institut du thorax, INSERM UMR1087 IRT, UN 8 quai Moncousu, BP 7072 44007 Nantes Cedex 1, France.

Received: 25 March 2014 Accepted: 18 August 2014

Published online: 05 September 2014

\section{References}

1. van den Berghe $G$, Wouters P, Weekers F, Verwaest $C$, Bruyninckx F, Schetz M, Vlasselaers D, Ferdinande P, Lauwers P, Bouillon R: Intensive insulin therapy in critically ill patients. N Engl J Med 2001, 345:1359-1367.

2. NICE-SUGAR Study Investigators, Finfer S, Chittock DR, Su SY, Blair D, Foster D, Dhingra V, Bellomo R, Cook D, Dodek P, Henderson WR, Hebert PC, Heritier S, Heyland DK, McArthur C, McDonald E, Mitchell I, Myburgh JA Norton R, Potter J, Robinson BG, Ronco JJ: Intensive versus conventional glucose control in critically ill patients. N Engl J Med 2009, 360:1283-1297.

3. Ichai C, Cariou A, Leone M, Veber B, Barnoud D, le Groupe d'Experts: Expert's formalized recommendations. Glycemic control in ICU and during anaesthesia: useful recommendations. Ann Fr Anesth Reanim 2009, 28:717-718. In French

4. Qaseem A, Humphrey LL, Chou R, Snow V, Shekelle P, Clinical Guidelines Committee of the American College of Physicians: Use of intensive insulin therapy for the management of glycemic control in hospitalized patients: a clinical practice guideline from the American College of Physicians. Ann Intern Med 2011, 154:260-267.

5. Yang M, Guo Q, Zhang X, Sun S, Wang Y, Zhao L, Hu E, Li C: Intensive insulin therapy on infection rate, days in NICU, in-hospital mortality and neurological outcome in severe traumatic brain injury patients: a randomized controlled trial. Int J Nurs Stud 2009, 46:753-758.

6. Graffagnino C, Gurram AR, Kolls B, Olson DM: Intensive insulin therapy in the neurocritical care setting is associated with poor clinical outcomes. Neurocrit Care 2010, 13:307-312.

7. Kruyt ND, Biessels GJ, Vriesendorp TM, Devries JH, Hoekstra JBL, Elbers PW, Kappelle $L J$, Portegies $P$, Vermeulen M, Roos: Subjecting acute ischemic stroke patients to continuous tube feeding and an intensive computerized protocol establishes tight glycemic control. Neurocrit Care 2010, 12:62-68.

8. NICE-SUGAR Study Investigators, Finfer $\mathrm{S}$, Liu B, Chittock DR, Norton R, Myburgh JA, McArthur C, Mitchell I, Foster D, Dhingra V, Henderson WR, Ronco JJ, Bellomo R, Cook D, McDonald E, Dodek P, Hébert PC, Heyland DK, Robinson BG: Hypoglycemia and risk of death in critically III patients. N Engl J Med 2012, 367:1108-1118.

9. Vespa P, McArthur DL, Stein N, Huang SC, Shao W, Filippou M, Etchepare M, Glenn T, Hovda DA: Tight glycemic control increases metabolic distress in traumatic brain injury. Crit Care Med 2012, 40:1923-1929.

10. Jeremitsky E, Omert LA, Dunham CM, Wilberger J, Rodriguez A: The impact of hyperglycemia on patients with severe brain injury. J Trauma 2005, 58:47-50.

11. Nurmi J, Boyd J, Anttalainen N, Westerbacka J, Kuisma M: Early increase in blood glucose in patients resuscitated from out-of-hospital ventricular fibrillation predicts poor outcome. Diabetes Care 2012, 35:510-512.

12. Godoy DA, Piñero GR, Svampa S, Papa F, Di Napoli M: Hyperglycemia and short-term outcome in patients with spontaneous intracerebral hemorrhage. Neurocrit Care 2008, 9:217-229.

13. Capes SE, Hunt D, Malmberg K, Pathak P, Gerstein HC: Stress hyperglycemia and prognosis of stroke in nondiabetic and diabetic patients: a systematic overview. Stroke 2001, 32:2426-2432.

14. Middleton S, McElduff P, Ward J, Grimshaw JM, Dale S, D'Este C, Drury P, Griffiths R, Cheung NW, Quinn C, Evans M, Cadilhac D, Levi C, QASC Trialists Group: Implementation of evidence-based treatment protocols to manage fever, hyperglycaemia, and swallowing dysfunction in acute stroke (QASC): a cluster randomised controlled trial. Lancet 2011, 378:1699-1706.

15. Chaudhuri A, Janicke D, Wilson MF, Tripathy D, Garg R, Bandyopadhyay A, Calieri J, Hoffmeyer D, Syed T, Ghanim H, Aljada A, Dandona P: Anti-inflammatory and profibrinolytic effect of insulin in acute ST-segment-elevation myocardial infarction. Circulation 2004, 109:849-854.

16. Jeschke $M G$, Klein $D$, Bolder $U$, Einspanier R: Insulin attenuates the systemic inflammatory response in endotoxemic rats. Endocrinology 2004, 145:4084-4093.
17. Kum W, Zhu SQ, Ho SK, Young JD, Cockram CS: Effect of insulin on glucose and glycogen metabolism and leucine incorporation into protein in cultured mouse astrocytes. Glia 1992, 6:264-268.

18. Bingham EM, Hopkins D, Smith D, Pernet A, Hallett W, Reed L, Marsden PK Amiel SA: The role of insulin in human brain glucose metabolism: an 18fluoro-deoxyglucose positron emission tomography study. Diabetes 2002, 51:3384-3390.

19. Feuerstein D, Manning A, Hashemi P, Bhatia R, Fabricius M, Tolias C, Pahl C, Ervine M, Strong AJ, Boutelle MG: Dynamic metabolic response to multiple spreading depolarizations in patients with acute brain injury: an online microdialysis study. J Cereb Blood Flow Metab 2010, 30:1343-1355.

20. Kalfon P, Giraudeau B, Ichai C, Guerrini A, Brechot N, Cinotti R, Dequin PF, Riu-Poulenc B, Montravers P, Annane D, Dupont H, Sorine M, Riou B: Tight computerized versus conventional glucose control in the ICU: a randomized controlled trial. Intensive Care Med 2014, 40:171-181.

21. Bullock MR, Povlishock JT: Guidelines for the management of severe traumatic brain injury. Editor's Commentary. J Neurotrauma 2007, 24 2 p, preceding $S 1$.

22. Brain Trauma Foundation, American Association of Neurological Surgeons, Congress of Neurological Surgeons, Joint Section on Neurotrauma and Critical Care, AANS/CNS, Bratton SL, Chestnut RM, Ghajar J, McConnell Hammond FF, Harris OA, Hartl R, Manley GT, Nemecek A, Newell DW, Rosenthal G, Schouten J, Shutter L, Timmons SD, Ullman JS, Videtta W, Wilberger JE, Wright DW: Guidelines for the management of severe traumatic brain injury. VIII. Intracranial pressure thresholds. J Neurotrauma 2007, 24:S55-S58.

23. Connolly ES, Rabinstein AA, Carhuapoma JR, Derdeyn CP, Dion J, Higashida RT, Hoh BL, Kirkness CJ, Naidech AM, Ogilvy CS, Patel AB, Thompson BG, Vespa P, American Heart Association Stroke Council, Council on Cardiovascular Radiology and Intervention, Council on Cardiovascular Nursing, Council on Cardiovascular Surgery and Anesthesia, and Council on Clinical Cardiology: Guidelines for the management of aneurysmal subarachnoid hemorrhage: a guideline for healthcare professionals from the American Heart Association/American Stroke Association. Stroke 2012, 43:1711-1737.

24. Ichai C, Payen JF, Orban JC, Quintard H, Roth $\mathrm{H}$, Legrand R, Francony G, Leverve XM: Half-molar sodium lactate infusion to prevent intracranial hypertensive episodes in severe traumatic brain injured patients: a randomized controlled trial. Intensive Care Med 2013, 39:1413-1422.

25. Rondeau N, Cinotti R, Rozec B, Roquilly A, Floch H, Groleau N, Michel P, Asehnoune K, Blanloeil Y: Dobutamine-induced high cardiac index did not prevent vasospasm in subarachnoid hemorrhage patients: a randomized controlled pilot study. Neurocrit Care 2012, 17:183-190.

26. Roberts I, Sydenham E: Barbiturates for acute traumatic brain injury. Cochrane Database Syst Rev 2012, 12, CD000033.

27. Nolan JP: Therapeutic hypothermia after cardiac arrest: an advisory statement by the advanced life support task force of the International Liaison Committee on Resuscitation. Circulation 2003, 108:118-121.

28. Clifton GL, Valadka A, Zygun D, Coffey CS, Drever P, Fourwinds S, Janis LS, Wilde E, Taylor P, Harshman K, Conley A, Puccio A, Levin HS, McCauley SR, Bucholz RD, Smith KR, Schmidt JH, Scott JN, Yonas H, Okonkwo DO: Very early hypothermia induction in patients with severe brain injury (the National Acute Brain Injury Study: Hypothermia II): a randomised trial. Lancet Neurol 2011, 10:131-139.

29. Bequette BW: Analysis of algorithms for intensive care unit blood glucose control. J Diabetes Sci Technol 2007, 1:813-824.

30. Kreymann KG, Berger MM, Deutz NEP, Hiesmayr M, Jolliet P, Kazandjiev G, Nitenberg G, van den Berghe G, Wernerman J, DGEM (German Society for Nutritional Medicine), Ebner C, Hartl W, Heymann C, Spies C, ESPEN (European Society for Parenteral and Enteral Nutrition): ESPEN guidelines on enteral nutrition: intensive care. Clin Nutr 2006, 25:210-223.

31. Rosenfeld JV, Maas Al, Bragge P, Morganti-Kossmann MC, Manley GT, Gruen RL: Early management of severe traumatic brain injury. Lancet 2012, 380:1088-1098.

32. Green DM, O'Phelan KH, Bassin SL, Chang CW, Stern TS, Asai SM: Intensive versus conventional insulin therapy in critically ill neurologic patients. Neurocrit Care 2010, 13:299-306.

33. Schlenk F, Vajkoczy P, Sarrafzadeh A: Inpatient hyperglycemia following aneurysmal subarachnoid hemorrhage: relation to cerebral metabolism and outcome. Neurocrit Care 2009, 11:56-63. 
34. Moro N, Ghavim S, Harris NG, Hovda DA, Sutton RL: Glucose administration after traumatic brain injury improves cerebral metabolism and reduces secondary neuronal injury. Brain Res 2013, 1535:124-136.

35. Vespa P, Boonyaputthikul R, McArthur DL, Miller C, Etchepare M, Bergsneider M, Glenn T, Martin N, Hovda D: Intensive insulin therapy reduces microdialysis glucose values without altering glucose utilization or improving the lactate/pyruvate ratio after traumatic brain injury. Crit Care Med 2006, 34:850-856.

36. Wyss MT, Jolivet R, Buck A, Magistretti PJ, Weber B: In vivo evidence for lactate as a neuronal energy source. J Neurosci 2011, 31:7477-7485.

37. Suh SW, Gum ET, Hamby AM, Chan PH, Swanson RA: Hypoglycemic neuronal death is triggered by glucose reperfusion and activation of neuronal NADPH oxidase. J Clin Invest 2007, 117:910-918.

38. Bonds DE, Miller ME, Bergenstal RM, Buse JB, Byington RP, Cutler JA, Dudl RJ, Ismail-Beigi F, Kimel AR, Hoogwerf B, Horowitz KR, Savage PJ, Seaquist ER, Simmons DL, Sivitz WI, Speril-Hillen JM, Sweeney ME: The association between symptomatic, severe hypoglycaemia and mortality in type 2 diabetes: retrospective epidemiological analysis of the ACCORD study. BMJ 2010, 340:b4909.

39. Kim F, Nichol G, Maynard C, Hallstrom A, Kudenchuk PJ, Rea T, Copass MK, Carlbom D, Deem S, Longstreth WT, Olsufka M, Cobb LA: Effect of prehospital induction of mild hypothermia on survival and neurological status among adults with cardiac arrest. JAMA 2014, 311:45-52.

40. Schierhout G, Roberts I: Anti-epileptic drugs for preventing seizures following acute traumatic brain injury. Cochrane Database Syst Rev 2001, 4, CD000173.

41. Pelosi P, Ferguson ND, Frutos-Vivar F, Anzueto A, Putensen C, Raymondos K, Apezteguia C, Desmery P, Hurtado J, Abroug F, Elizalde J, Tomicic V, Cakar N, Gonzalez M, Arabi Y, Moreno R, Esteban A: Management and outcome of mechanically ventilated neurologic patients. Crit Care Med 2011, 39:1482-1492.

42. Kahn JM, Caldwell EC, Deem S, Newell DW, Heckbert SR, Rubenfeld GD: Acute lung injury in patients with subarachnoid hemorrhage: incidence, risk factors, and outcome. Crit Care Med 2006, 34:196-202.

43. Roquilly A, Cinotti R, Jaber S, Vourc'h M, Pengam F, Mahe PJ, Lakhal K, Demeure Dit Latte D, Rondeau N, Loutrel O, Paulus J, Rozec B, Blanloeil Y, Vibet MA, Sébille V, Feuillet F, Asehnoune K: Implementation of an evidence-based extubation readiness bundle in 499 brain-injured patients. A before-after evaluation of a quality improvement project. Am J Respir Crit Care Med 2013, 188:958-966.

doi:10.1186/s13054-014-0498-9

Cite this article as: Cinotti et al:: Effects of tight computerized glucose control on neurological outcome in severely brain injured patients: a multicenter sub-group analysis of the randomized-controlled open-label CGAO-REA study. Critical Care 2014 18:498.

\section{Submit your next manuscript to BioMed Central and take full advantage of:}

- Convenient online submission

- Thorough peer review

- No space constraints or color figure charges

- Immediate publication on acceptance

- Inclusion in PubMed, CAS, Scopus and Google Scholar

- Research which is freely available for redistribution 